\title{
Coagulation/Flocculation/Sedimentation Applied to Marble Processing Wastewater Treatment
}

\author{
Asimina E. Domopoulou ${ }^{1}$, Konstantinos H. Gudulas ${ }^{1}$, Efthimios S. Papastergiadis ${ }^{2}$ \& Vayos G. Karayannis ${ }^{1}$ \\ ${ }^{1}$ Department of Environmental Engineering, Technological Education Institute of Western Macedonia, Kozani, \\ Greece \\ ${ }^{2}$ Department of Food Technology, Alexander Technological Education Institute of Thessaloniki, Thessaloniki, \\ Greece \\ Correspondence: Vayos G. Karayannis, Department of Environmental Engineering, Technological Education \\ Institute of Western Macedonia, 50100, Kozani, Greece. Tel: 30-246-106-8022. E-mail: vkarayan@teiwm.gr
}

Received: December 7, 2014

Accepted: January 2, 2015 Online Published: April 26, 2015

doi:10.5539/mas.v9n6p137

URL: http://dx.doi.org/10.5539/mas.v9n6p137

\begin{abstract}
In the current work, the application of chemical coagulation/flocculation/sedimentation, an established and low cost method, to marble processing wastewater treatment is studied, and the optimum conditions for the maximum solid waste removal are investigated. The environmental impact from the operation of a modern marble processing plant is actually important, due to the consumption of high amounts of water resulting in the production of high effluent volumes, and therefore particular efforts are made for the efficient wastewater treatment in order to recover and reuse the effluents of the process, and avoid uncontrolled discharge and disposal of solid residue from the primary wastewater treatment. For that purpose, hydrated metal salts including $\mathrm{Al}_{2}\left(\mathrm{SO}_{4}\right)_{3} \cdot 18 \mathrm{H}_{2} \mathrm{O}, \mathrm{FeCl}_{3} \cdot 6 \mathrm{H}_{2} \mathrm{O}$ and $\mathrm{FeSO}_{4} \cdot 7 \mathrm{H}_{2} \mathrm{O}$ were examined for their turbidity removal capacity under various dosages and studied in relation to the wastewater $\mathrm{pH}$ and electrical conductivity. Jar test results showed that $\mathrm{FeCl}_{3} \cdot 6 \mathrm{H}_{2} \mathrm{O}$ presented the highest turbidity removal ability at doses of about $0.375 \mathrm{~g} / \mathrm{L}$, while the poorest coagulation/flocculation potential was found for $\mathrm{FeSO}_{4} 7 \mathrm{H}_{2} \mathrm{O}$. The findings of this study are expected to contribute to the preparation of a strategic plan for the integrated management of marble processing operations with a lower environmental footprint.
\end{abstract}

Keywords: marble processing wastewater, treatment, coagulation/flocculation/sedimentation, turbidity, $\mathrm{pH}$, electrical conductivity

\section{Introduction}

The industry of marble processing is considered one of the most important industrial sectors in Greece. The region of Western Macedonia (Northwestern Greece) in particular, is one of the main sources of marble in the country, characterized by a broad variety of white and colored marbles and other stones that are used today in the marble industry (Domopoulou et al., 2014).

The processing of marble towards the production of final saleable material entails cutting the raw ore into plates of defined shapes and sizes followed by grinding and polishing of visible surfaces. Each stage involves water recirculation aiming at cooling down the cutting and polishing equipment and also removing fine dust particles. The produced wastewater throughout the various stages of processing results in the creation of a high-in-solids effluent, i.e. a sludge stream known as 'Mourgana'.

The operation of a modern marble processing plant arises significant environmental issues (Capitano et al., 2014). Especially water quality is of high importance for safe cutting and shaping processes, and therefore the water used in the marble processing industry is required to be of good quality, without containing any suspended solids or salts (Oates, 1998). When a drinking water supply system is not available, alternative water sources, such as individual water drills, may be used. In these cases, water quality should be monitored and appropriate methods should be employed to attain the required chemical and physical water properties. However, fresh water cost is usually high, given the high volumes consumed, and thereby it is more advantageous to recycle the used water, thus contributing to the development of an environmentally-friendly process with a low water footprint. Hence, the most important issue, associated with water used in marble processing is the application of a cost-effective 
technique for the removal of solid particles incurred during cutting, and the recovery, recycling and reuse of the treated effluent in the marble processing devices.

Today, various techniques are employed for water recovery and recycling (Matouq et al., 2014; Al Ansari, 2012; Ntampegliotis et al., 2006). Coagulation/flocculation, in particular, has been extensively used due to its low cost and simple operation. This method induces the most suitable environment that should impact on coagulation/flocculation mechanisms and subsequent floc formation. It can be achieved by adding a suitable reagent as coagulant/flocculant, under vigorous stirring conditions aiming at a uniform dispersion of the reagent, the destabilization of the colloid micelles and the formation of small aggregates. The growth of the aggregates towards larger and heavier flocs of appropriate size, which are then removed by precipitation, is achieved by slow agitation that enhances the movement of the aggregates and their attenuation in small distances (Harif et al., 2012; Duan \& Gregory, 2003).

The coagulation/flocculation aids used in the past were inorganic polymeric compounds, such as silica and other natural polymers. Synthetic polymers are frequently used today as coagulation/flocculation reagents. Aluminium and iron salts in particular, are widely used as coagulants/flocculants in water and wastewater treatment, as they are effective in removing a broad range of impurities from water, including colloidal particles and dissolved organic substances (Feng et al., 2015; Harif et al., 2012; Petala et al., 2006; Duan \& Gregory, 2003). Several factors may affect the coagulation/flocculation process, such as the type of chemical agent and dosage, $\mathrm{pH}$, water properties, temperature etc.

In general, coagulation/flocculation/sedimentation is a universal method, as it eliminates a large number of substances, with various particle weights. It is employed in drinking water treatment for particle removal involving the addition of an appropriate compound (coagulant/flocculant) in the process water. In wastewater treatment, an essential feature of coagulation/flocculation processes is to remove the colloidal material that causes coloration and turbidity, eliminating SS and as much of the organic material as possible (Chowdhury et al., 2013; Sher et al., 2013; Syafalni et al., 2012; Arvanitoyannis \& Ladas, 2008). For marble processing wastewater treatment in particular, physicochemical methods have been considered in the last years (Ozyonar \& Karagozoglu, 2012; Solak et al., 2009; Arslan et al., 2005; Ersoy, 2005).

The aim of the present work was the application of the coagulation/flocculation/sedimentation process to the treatment of marble processing wastewater and the determination of optimum conditions, i.e. type of chemical agent, doses and $\mathrm{pH}$, in order to obtain treated water of high quality.

\section{Materials and Methods}

Wastewater samples were collected from two different marble processing plants in the region of Western Macedonia, Greece. The mineralogical composition of marbles derived from this area consists in $98 \%$ calcite, $1 \%$ dolomite, $0.5 \%$ quartz and $0.5 \%$ muscovite $0.5 \%$ respectively. The chemical composition of these marbles is shown in Table 1. The main physico-chemical properties of the wastewaters examined are given in Table 2.

Table 1. Chemical composition (\%) of marbles from Western Macedonia, Greece

\begin{tabular}{ccccccccc}
$\mathbf{C a O}$ & $\mathbf{M g O}$ & $\mathbf{S i O}_{2}$ & $\mathbf{F e}_{2} \mathbf{O}_{3}$ & $\mathbf{A l}_{2} \mathbf{O}_{3}$ & $\mathbf{K}_{2} \mathbf{O}$ & $\mathbf{N a}_{\mathbf{2}} \mathbf{O}$ & $\mathbf{M n O}$ & $\mathbf{C O}_{2}$ \\
\hline 53.50 & 1.52 & 0.25 & 0.18 & 0.25 & 0.02 & 0.04 & 0.01 & 44.4 \\
\hline
\end{tabular}

Table 2. Properties of wastewater samples from two marble processing plants

\begin{tabular}{lcc}
\hline Parameters & Sample 1 & Sample 2 \\
\hline Temperature $\left({ }^{\circ} \mathrm{C}\right)$ & 20 & 20 \\
pH & 5.4 & 8.17 \\
Conductivity & 2.01 & 684 \\
$(\mu \mathrm{S} / \mathrm{cm})$ & 396 & 6450 \\
Turbidity (NTU) & & \\
\hline
\end{tabular}

All chemical reagents used in this study were of analytical grade. Deionised water was used for the preparation of aqueous solutions. Three hydrated coagulants/flocculants were examined for their solids removal potential, namely aluminum sulfate 18 -hydrate $\left(\mathrm{Al}_{2}\left(\mathrm{SO}_{4}\right)_{3} \cdot 18 \mathrm{H}_{2} \mathrm{O}\right)$, ferric chloride 6-hydrate $\left(\mathrm{FeCl}_{3} \cdot 6 \mathrm{H}_{2} \mathrm{O}\right)$ and ferric sulfate 7-hydrate $\left(\mathrm{FeSO}_{4} \cdot 7 \mathrm{H}_{2} \mathrm{O}\right)$. All coagulants were prepared in $0.1 \mathrm{M}$ stock solution. Volumes of stock solutions were added to $800 \mathrm{~mL}$ sample volumes to obtain the desired final metal salt solutions: 100, 200, 300 and $400 \mathrm{mg} / \mathrm{L}$ for aluminum sulfate and for ferric chloride, and 250, 550, 800, $1050 \mathrm{mg} / \mathrm{L}$ for ferric sulfate. 
A jar-test apparatus (Figure 1) was used for the coagulation/flocculation experiments equipped with four $800 \mathrm{~mL}$ beakers; all runs were conducted at room temperature $\left(20^{\circ} \mathrm{C}\right)$.

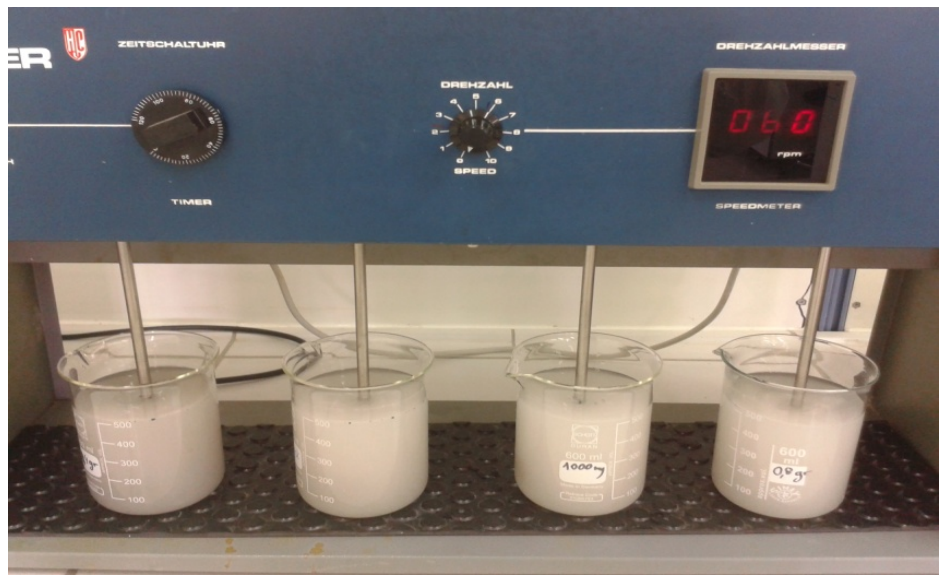

Figure 1. Jar test apparatus

$800 \mathrm{~mL}$ of wastewater sample was added into the beakers followed by the addition of the appropriate volume of the metal salt stock solution. The mixture was rapidly mixed at $160 \mathrm{rpm}$ for $2 \mathrm{~min}$, followed by a slow stirring period at $60 \mathrm{rpm}$ for $10 \mathrm{~min}$. Finally, the mixture was allowed to settle for $20 \mathrm{~min}$, and a sample was withdrawn from the supernatant for further analysis. Kinetic studies were carried out by the collection of $25 \mathrm{~mL}$ samples at various time intervals at the end of the slow stirring period, i.e. at 5, 10, 15, 20, and $30 \mathrm{~min}$.

The water samples were analyzed for the determination of $\mathrm{pH}$ using an Orion $710 \mathrm{~A}$ pHmeter, electrical conductivity using a Crison EC-meter GLP 31+ conductivity meter and turbidity by a LaMotte 2020we turbidity meter. The sediment obtained was analyzed using XRD and SEM-EDX analysis.

\section{Results and Discussion}

The experimental results of the jar tests, including the effect of various chemicals and doses on the water quality are given in Figures $2 \mathrm{a}$ and b. $\mathrm{pH}$ is often regarded as the most important water quality parameter, as certain chemical processes take place only at a specific $\mathrm{pH}$ value. The mode of action of coagulants/flocculants in particular, is generally explained in terms of two distinct mechanisms depending precisely on $\mathrm{pH}$ and coagulant/flocculant dosage: charge neutralisation of negatively charged colloids by cationic hydrolysis products and incorporation of impurities in an amorphous hydroxide precipitate. As shown in Figures $2 \mathrm{a}$ and $\mathrm{b}, \mathrm{pH}$ varied with the incremental doses of the reagents used for the coagulation/flocculation treatment. Moreover, for $\mathrm{Al}_{2}\left(\mathrm{SO}_{4}\right)_{3} \cdot 18 \mathrm{H}_{2} \mathrm{O}$ and $\mathrm{FeCl}_{3} \cdot 6 \mathrm{H}_{2} \mathrm{O}$, treated wastewater presented rather neutral $\mathrm{pH}$ values, in the range of 6.5-8. Use of $\mathrm{FeSO}_{4} \cdot 7 \mathrm{H}_{2} \mathrm{O}$ however, lead to decreased $\mathrm{pH}$ values ranging between about 3.5 and 5 . With regard to electrical conductivity, the measurements in Figures $2 \mathrm{a}$ and $2 \mathrm{~b}$ show that increasing the coagulant dose results in slight increase of electrical conductivity. Also from Figures $2 \mathrm{a}$ and $\mathrm{b}$, the type and dosage of the coagulant greatly affected the water quality and particularly the turbidity of the effluent. Hydrated aluminum sulfate and ferric trichloride proved to be the most efficient coagulants/flocculant during treatment of sample 1 (Figure 2a), resulting in low water turbidity ranging from 17 to 24 NTU for the aluminum salt and even down to 1-2 NTU for the ferric salt, while much higher turbidity values were observed for the sample 1 treated with ferric sulfate. Although the initial wastewater properties are important for a successful treatment (Careddu et al., 2014), and the unprocessed sample 2 presented high initial turbidity, again aluminum sulfate and ferric trichloride proved to be efficient coagulation/flocculation reagents (Figure 2b), leading to low water turbidity ranging between 12 and 24 NTU, while higher values were measured for ferric sulfate varying from 25 to 95 NTU. In addition, for wastewater sample 1, metal salt dosage slightly affected the process efficiency for the aluminum and the ferric chloride salts, but greatly affected the ferric sulfate behavior.

Turbidity is an indication of the concentration of colloidal particles and is considered an important parameter for evaluating the quality of a water sample. The higher the particle count, the more turbid the water is. These colloidal particles have, in most cases, a negative surface charge, as already mentioned, resulting in the development of repulsion forces between them. Therefore, it is important to promote the destabilization of the particles by adding cationic chemical reagents. The latter stages of water treatment depend largely on the success of the coagulation/flocculation/sedimentation process. The effect of coagulant/flocculant dose on the removal 
efficiency of turbidity for wastewater samples 1 and 2 is depicted in Figure $3 \mathrm{a}$ and $3 \mathrm{~b}$.
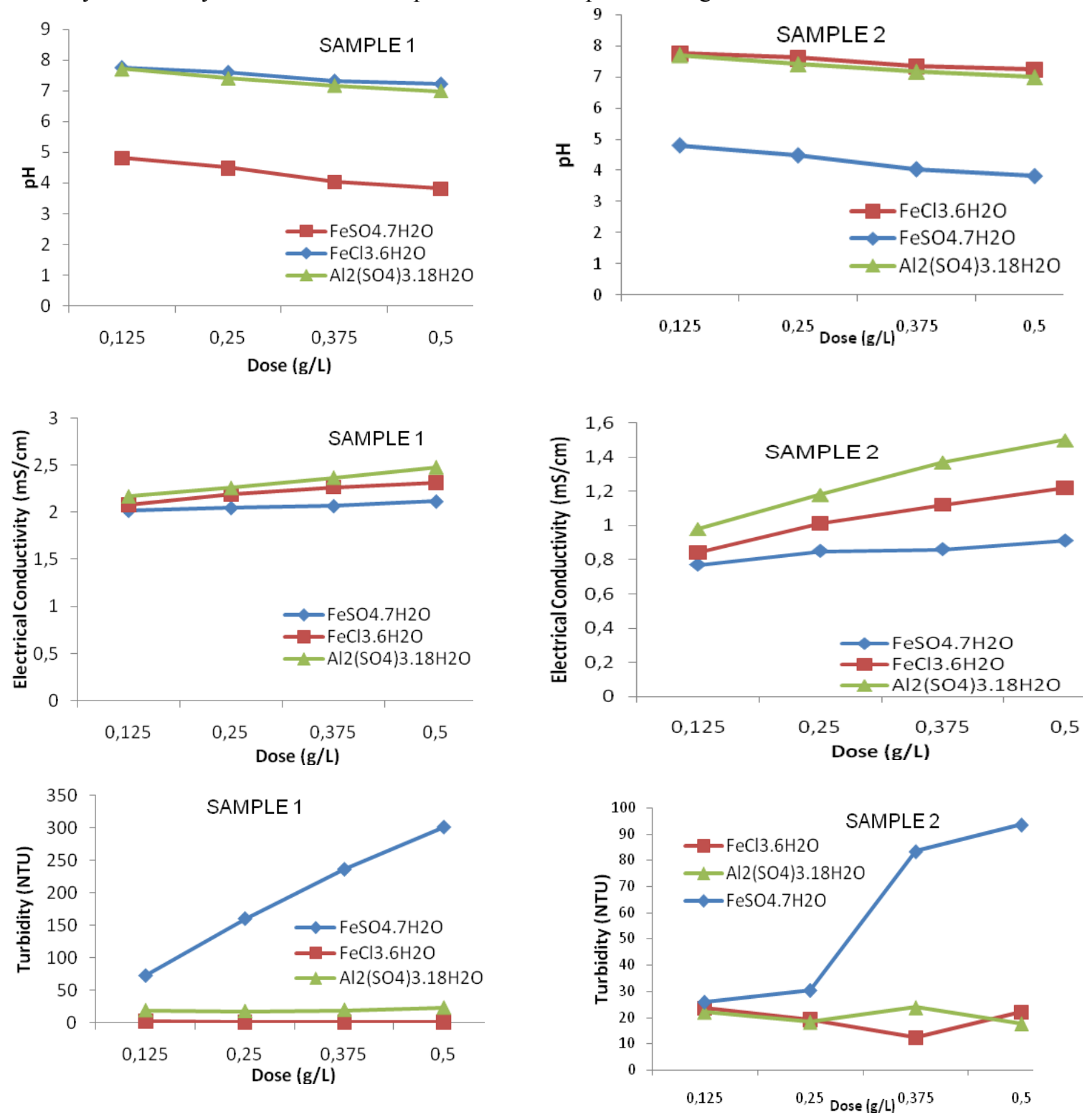

(a)

(b)

Figure 2. pH, electrical conductivity and turbidity of treated marble wastewater sample 1 (a) and sample 2 (b) as a function of coagulant dose

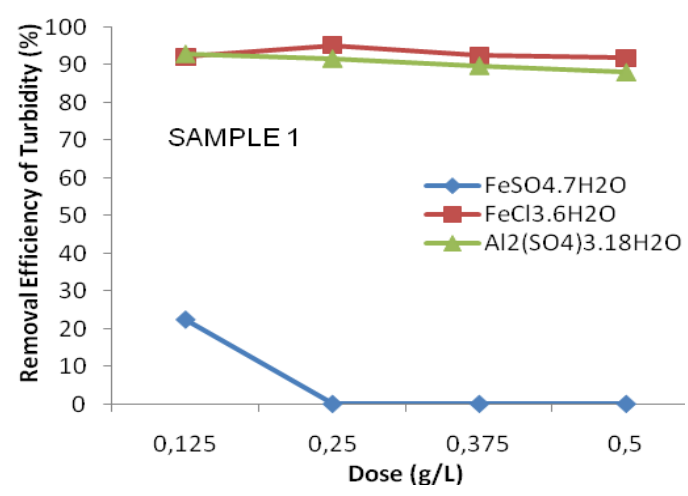

(a)

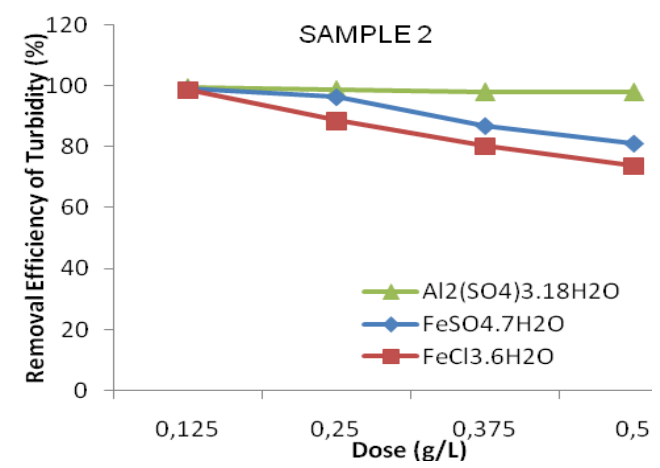

(b)

Figure 3. Effect of coagulant dose on removal of turbidity for wastewater sample 1 (a) and 2 (b) 
From Figure 3, it can be concluded that the turbidity removal rate for wastewater sample 1 (a) ranged between 88-93\% for $\mathrm{Al}_{2}\left(\mathrm{SO}_{4}\right)_{3} \cdot 18 \mathrm{H}_{2} \mathrm{O}$, and $91-92 \%$ for $\mathrm{FeCl}_{3} \cdot 6 \mathrm{H}_{2} \mathrm{O}$, independent of dosage, while $\mathrm{FeSO}_{4} \cdot 7 \mathrm{H}_{2} \mathrm{O}$ showed unsufficient turbidity removal capacity. For sample 2 (b), the highest turbidity reduction rates, as much as 98-99.5\% were observed with $\mathrm{Al}_{2}\left(\mathrm{SO}_{4}\right)_{3} \cdot 18 \mathrm{H}_{2} \mathrm{O}$.

The efficiency of the coagulation/flocculation process as a function of time and dosage is revealed in Figures $4 \mathrm{a}$ and $4 \mathrm{~b}$ for wastewater samples 1 and 2 .
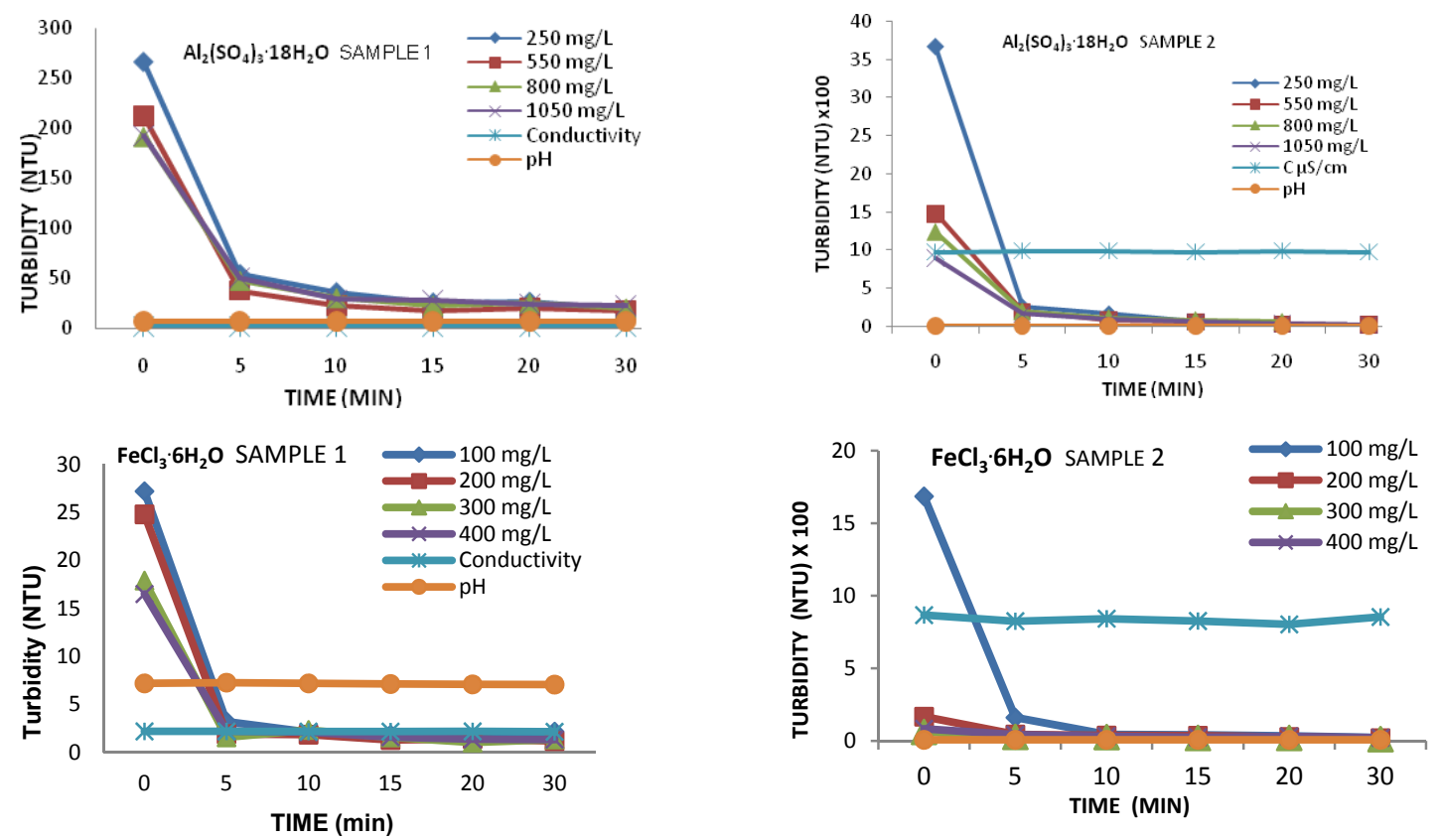

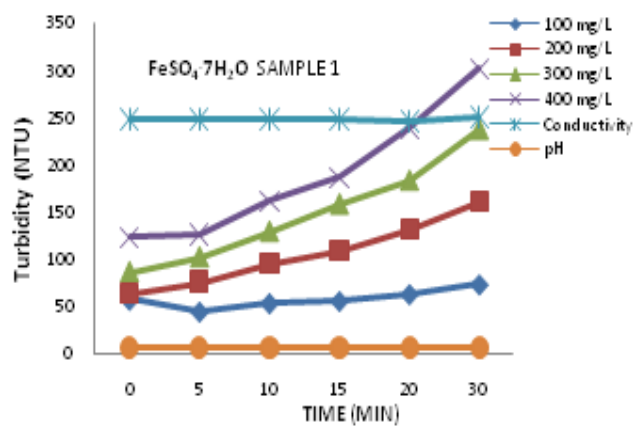

(a)

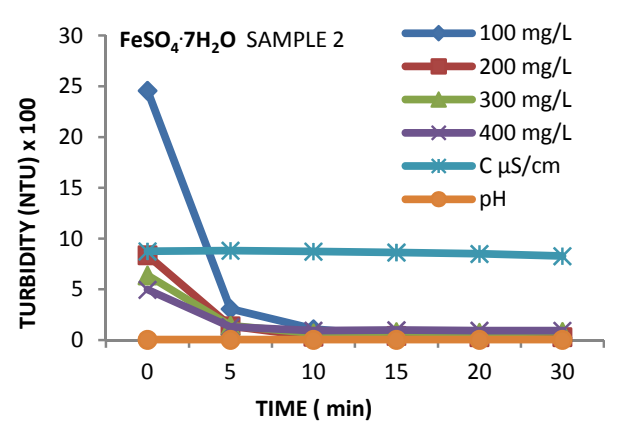

(b)

Figure 4. Variation of turbidity vs time (min) for marble wastewater sample 1 (a) and 2 (b)

From Figures $4 \mathrm{a}$ and $4 \mathrm{~b}$, it should be emphasized that significant reduction of turbidity, attaining about $95-99 \%$ removal capacity, is achieved even at the early stage of the reaction, corresponding to as short process times as $5 \mathrm{~min}$.

Figure 5 provides visualization through SEM-EDAX of the flocculates obtained in the sediment recovered from the coagulation/flocculation process. A fine and uniform dispersion of the coagulant/flocculant reagent in the marble residue achieved by adding hydrated aluminum sulfate (Figure 5a) should contribute to the destabilization of the colloid micelles and the formation of aggregates, thus explaining its efficiency for marble processing wastewater treatment. Nevertheless, relatively uniform dispersion is also attained with hydrated ferric chloride (Figure 5b), which was also proved to be a suitable coagulant/flocculant. On the other hand, the reduced turbidity removal capacity already stated for the hydrated ferric sulfate should be associated with a poorer dispersion of the reagent, as it can be seen in Figure 5c.

Furthermore, representative XRD analysis spectra are presented in Figure 6, which show a prevailing dolomite phase in the marble sediment recovered from the coagulation/flocculation process. Certainly, calcite is also detected. 

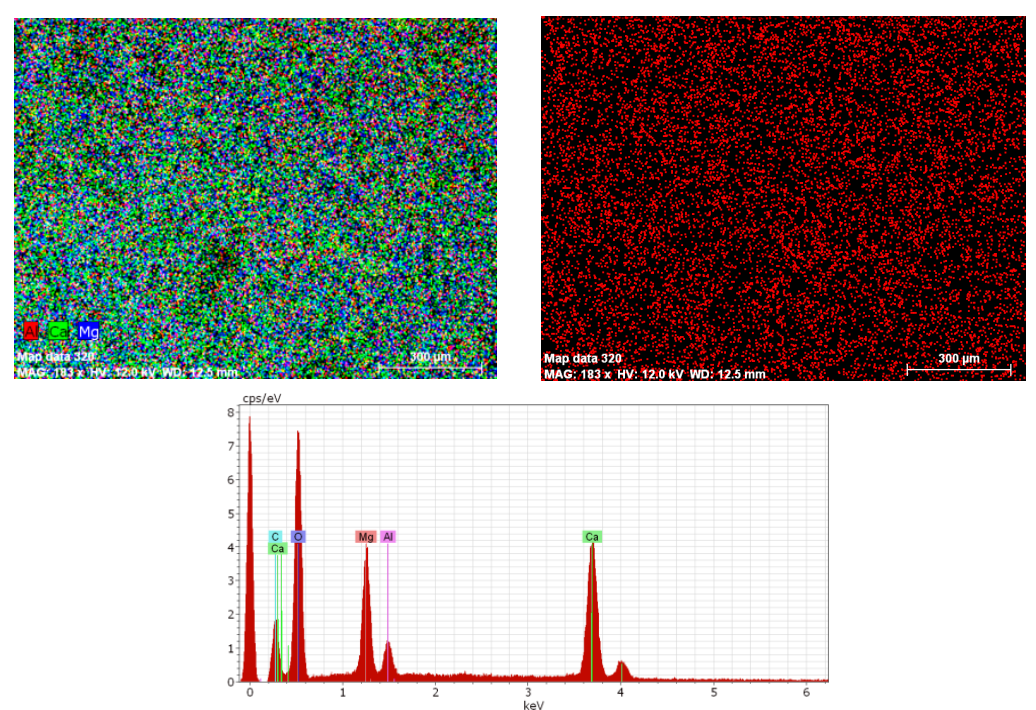

(a)
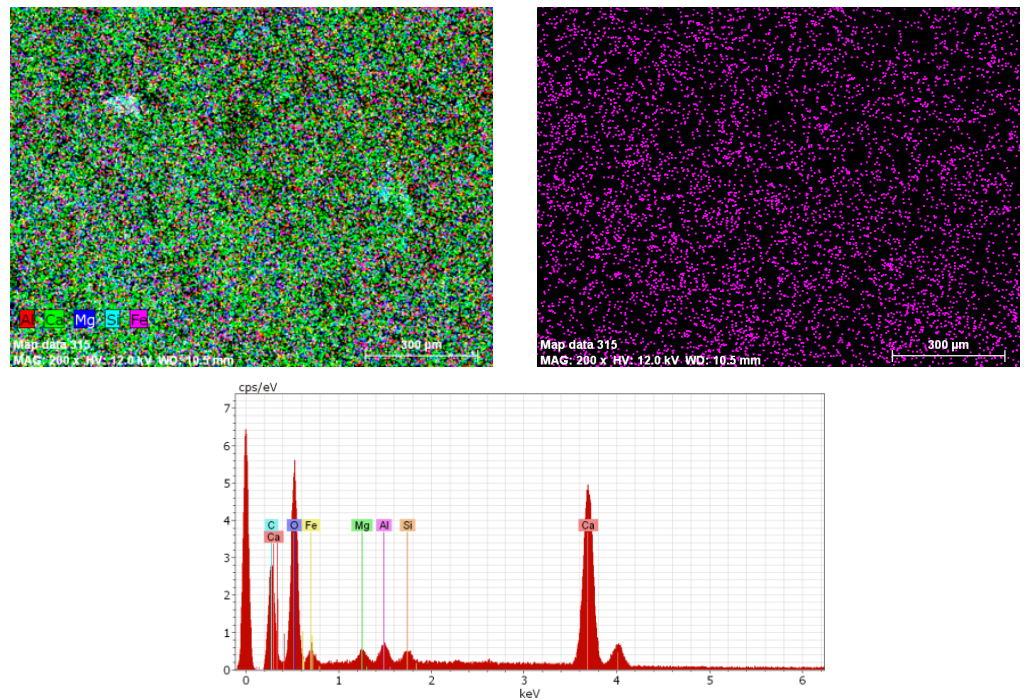

(b)
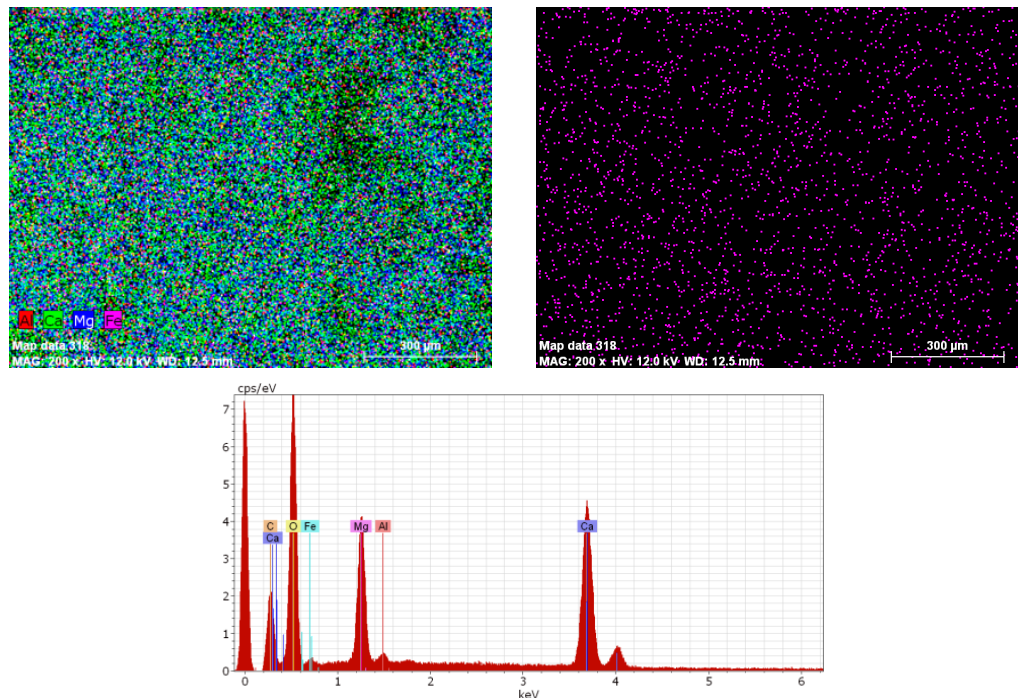

(c)

Figure 5. SEM micrographs with chemical mapping of sediment recovered from marble processing wastewater treatment using hydrated salts as coagulants/flocculants: aluminum sulfate (a), ferric chloride (b) and sulfate (c) 


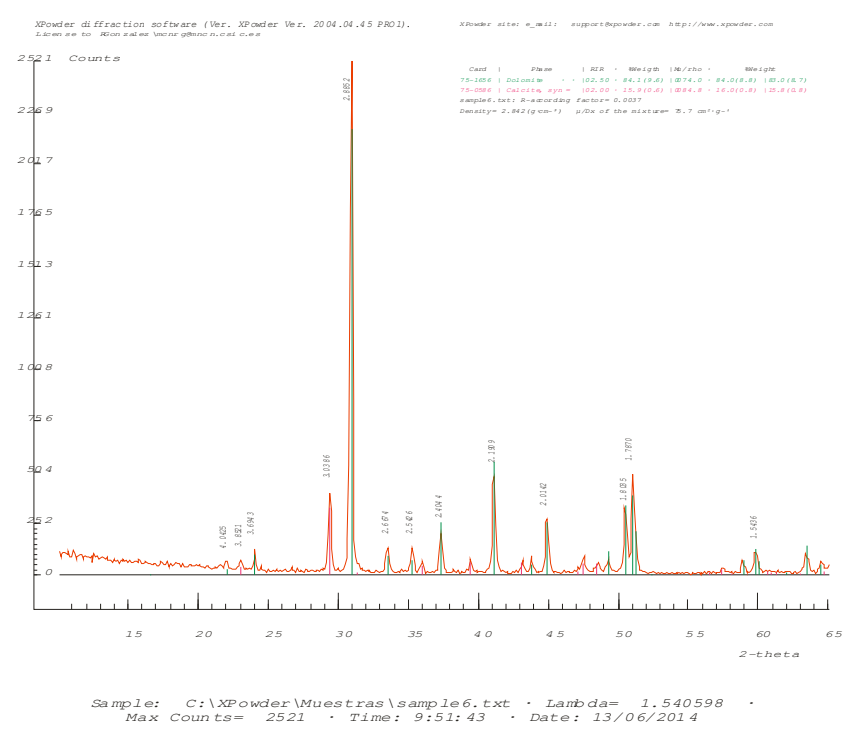

Figure 6. Representative XRD spectra of sediment recovered from marble processing wastewater treatment using hydrated salts as coagulants/flocculants

\section{Conclusions}

Marble processing wastewater treatment is achieved by chemical coagulation/flocculation/sedimentation process. Concluding:

- Among the hydrated metal salts $\left(\mathrm{Al}_{2}\left(\mathrm{SO}_{4}\right)_{3} \cdot 18 \mathrm{H}_{2} \mathrm{O}, \mathrm{FeCl}_{3} \cdot 6 \mathrm{H}_{2} \mathrm{O}\right.$ and $\left.\mathrm{FeSO}_{4} \cdot 7 \mathrm{H}_{2} \mathrm{O}\right)$ studied by varying the reagent dosage and $\mathrm{pH}$, the ferric chloride proves to be the most efficient coagulant/flocculant, resulting in an effluent with negligible turbidity, followed in treatment performance by aluminum sulfate, while ferric sulfate presents very low coagulation/flocculation ability.

- The hydrated ferric trichloride and aluminum sulfate prove to be efficient coagulation/flocculation reagents for treating wastewater even with high initial turbidity.

- Kinetic studies reveal a high turbidity removal rate to as short sedimentation times as $5 \mathrm{~min}$. The optimum removal efficiency in shorter operation time is a strong advantage of the method employed.

- Chemical dosage slightly affects the process efficiency in most cases. Moreover, $\mathrm{pH}$ does not significantly changes with ferric trichloride and aluminum sulfate, resulting in treated water samples with $\mathrm{pH}$ in the range of 6.5-8.0. However, clear $\mathrm{pH}$ reduction is observed by the addition of ferric sulfate resulting in $\mathrm{pH}$ values between 3.5 and 5.0.

The results of the current research are expected to contribute to the preparation of a strategic plan for an integrated management of marble processing operations with the lowest possible environmental footprint.

\section{Acknowledgment}

This research has been financed through the Research Program "Integrated management of solid and liquid effluents from marble processing plants" (Scientific Coordinator: Assist. Professor Asimina Domopoulou) funded by the Specific Account Research Committee of Technological Education Institute of Western Macedonia (ELKE - TEI WM), Greece.

\section{References}

Al Ansari, M. S. (2012). A review of optimal designs in relation to supply chains and sustainable chemical processes. Modern Applied Science, 6(12), 74-85. http://dx.doi.org/10.5539/mas.v6n12p74

Arslan, E. I., Aslan, S., Ipek, U., Altun, S., \& Yazicioglu, S. (2005). Physico-chemical treatment of marble processing wastewater and the recycling of its sludge. Waste Management \& Research, 23, 550-559. http://dx.doi.org/10.1177/0734242x05059668

Arvanitoyannis, I. S. \& Ladas, D. (2008). Meat waste treatment methods and potential uses. International Journal of Food Science and Technology, 43, 543-559. http://dx.doi.org/10.1111/j.1365-2621.2006.01492.x

Capitano, C., Peri, G. \& Rizzo, G. (2014). Is the Eco-label EU Decision for hard coverings really capable of capturing the environmental performances of the marble productive chain? A field verification by means of 
a life cycle approach. International Journal of Life Cycle Assessment, 19(5), 1022-1035. http://dx.doi.org/10.1007/s11367-014-0718-1

Careddu, N., Marras, G. \& Siotto, G. (2014). Recovery of sawdust resulting from marble processing plants for future uses in high value-added products. Journal of Cleaner Production, 84, 533-539. http://dx.doi.org/10.1016/j.jclepro.2013.11.062

Chowdhury, M., Mostafa, M. G., Biswas, T. K. \& Saha, A. K. (2013). Treatment of leather industrial effluents by filtration and coagulation processes. Water Resources and Industry, 3, 11-22. http://dx.doi.org/10.1016/j.wri.2013.05.002

Domopoulou, A. E., Spiliotis, X. D., Ntampegliotis, K. I., Gudulas, K. H., Papapolymerou, G. A.-P. \& Karayannis, V. G. (2014). Compacted ceramics incorporating recycled marble processing residue. Journal of International Scientific Publications: Materials, Methods and Technologies, 8, ISSN 1314-7269, 786-791.

Duan, J. \& Gregory, J. (2003). Coagulation by hydrolysing metal salts. Advances in Colloid and Interface Science, 100-102, 475-502. http://dx.doi.org/10.1016/s0001-8686(02)00067-2

Ersoy, B. (2005). Effect of $\mathrm{pH}$ and polymer charge density on settling rate and turbidity of natural stone suspensions. Int. J. Miner. Process., 75, 207-216. http://dx.doi.org/10.1016/j.minpro.2004.08.011

Feng, L., Wang, W., Feng, R., Zhao, S., Dong, H., Sun, S., Gao, B., \& Yue, Q. (2015). Coagulation performance and membrane fouling of different aluminum species during coagulation/ultrafiltration combined process. Chemical Engineering Journal, 262, 1161-1167. http://dx.doi.org/10.1016/j.cej.2014.10.078

Harif, T., Khai, M., \& Adin, A. (2012). Electrocoagulation versus chemical coagulation: Coagulation/flocculation mechanisms and resulting floc characteristics. Water Research, 46, 3177-3188. http://dx.doi.org/10.1016/j.watres.2012.03.034

Matouq, M., Al-Anber, Z., Susumu, N., Tagawa, T., \& Karapanagioti, H. (2014). The kinetic of dyes degradation resulted from food industry in wastewater using high frequency of ultrasound. Separation and Purification Technology, 135, 42-47. http://dx.doi.org/10.1016/j.seppur.2014.08.002

Ntampegliotis, K., Riga, A., Karayannis, V., Bontozoglou, V., \& Papapolymerou, G. (2006). Decolorization kinetics of Procion H-exl dyes from textile dyeing using Fenton-like reactions. Journal of Hazardous Materials, 136(1), 75-84. http://dx.doi.org/10.1016/j.jhazmat.2005.11.016

Oates, J. A. H. (1998). Lime and limestone. Chemistry and Technology, Production and Uses, Weinheim, Wiley VCH. http://dx.doi.org/10.1002/9783527612024

Ozyonar, F., \& Karagozoglu, B. (2012). Systematic assessment of electrocoagulation for the treatment of marble processing wastewater. International Journal of Environmental Science and Technology, 9(4), 637-646. http://dx.doi.org/10.1007/s13762-012-0093-z

Petala, M., Samaras, P., Kungolos, A., Zouboulis A., Papadopoulos, A., \& Sakellaropoulos, G. P. (2006). The effect of coagulation on the toxicity and mutagenicity of reclaimed municipal effluents. Chemosphere, 65(6), 1007-1018. http://dx.doi.org/10.1016/j.chemosphere.2006.03.035

Sher, F., Malik, A., \& Liu, H. (2013). Industrial polymer effluent treatment by chemical coagulation and flocculation. Journal of Environmental Chemical Engineering, 1, 684-689. http://dx.doi.org/10.1016/j.jece.2013.07.003

Solak, M., Kilic, M., Yazici, H., \& Sencan, A. (2009). Removal of suspended solids and turbidity from marble processing wastewaters by electrocoagulation. Journal of Hazardous Materials, 172, 345-352. http://dx.doi.org/10.1016/j.jhazmat.2009.07.018

Syafalni, S., Abustan, I., Ismail, N., \& Kwan, T. S. (2012). Production of bioflocculant by Chryseomonas luteola and its application in dye wastewater treatment. Modern Applied Science, 6(5), 13-20. http://dx.doi.org/10.5539/mas.v6n5p13

\section{Copyrights}

Copyright for this article is retained by the author(s), with first publication rights granted to the journal.

This is an open-access article distributed under the terms and conditions of the Creative Commons Attribution license (http://creativecommons.org/licenses/by/3.0/). 